\begin{tabular}{|c|c|c|}
\hline 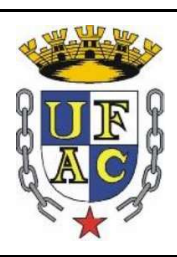 & $\begin{array}{c}\text { UÁQUIRI } \\
\text { Revista do Programa de Pós-Graduação em Geografia } \\
\text { UÁQUIRI - PPGGEO, v. 03, n. 01, p. 06-24, ano } 2021 \\
\text { Home page: } \underline{\text { http://revistas.ufac.br/revista/index.php/SciNat }}\end{array}$ & PPG \\
\hline & & SSN: 2675-4088 \\
\hline
\end{tabular}

\title{
A IMPORTÂNCIA DA REVOLUÇÃO ACREANA NO PROCESSO DE FORMAÇÃO DO ESTADO DO ACRE
}

\author{
Maria Cecília Pereira Ugalde ${ }^{1 *}$, ${ }^{\mathrm{r}}$ Charlys Roweder ${ }^{2}$, ${ }^{\mathrm{r}}$ Cleilton Sampaio de Farias ${ }^{2}$ \\ ORCID: https://orcid.org/0000 -0003-4493-5441: https://orcid.org/0000-0003-0348-2979; \\ https://orcid.org/0000 -0003-1783-3175
}

\begin{abstract}
${ }^{1}$ Discente do Instituto Federal do Acre, Programa de Pós-graduação em Educação Profissional e TecnológicaPROFEPT, Rio Branco, Acre, Brasil; ${ }^{2}$ Professor do Instituto Federal do Acre, Programa de Pós-graduação em Educação Profissional e Tecnológica-PROFEPT, Rio Branco, Acre, Brasil;

${ }^{2}$ Professor do Instituto Federal do Acre, Programa de Pós-graduação em Educação Profissional e TecnológicaPROFEPT, Rio Branco, Acre, Brasil.

*maria.ugalde@ifac.edu.br
\end{abstract}

Recebido em: 07/06/2021. Aceito em: 24/06/2021. Publicado em: 30/07/2021

DOI: https://doi.org/10.47418/uaquiri.vol3.n1.2021.5106

\begin{abstract}
Resumo
Esse artigo descreve o período histórico de anexação do Acre ao território brasileiro, abordando acontecimentos que vão desde os acordos assinados entre Portugal e Espanha, a série de conflitos decorrentes de interesses econômicos, que culminaram com o movimento armado conhecido como "Revolução Acreana" e, assinatura do Tratado de Petrópolis, em 1903, no qual a região passou a pertencer definitivamente ao Brasil. O Acre foi decretado Território Federal em 1904 e somente em 1962 passou à condição de Unidade da Federação. Assim, objetivou-se discutir a importância da Revolução Acreana para a formação do território acreano. Para tanto, foi realizada pesquisa de natureza qualitativa, do tipo bibliográfica e documental, por se adequar aos estudos exploratórios e a utilização de material elaborado, constituído principalmente por livros e artigos científicos. Em termos de ocupação é possível inferir que a Revolução Acreana foi fundamental para que as terras, constante nos antigos mapas bolivianos como "tierras nom descubiertas", fossem anexadas ao Brasil. Essa luta armada envolvendo brasileiros e bolivianos, gerou um acréscimo considerável as riquezas nacionais, assim como originou uma sociedade mista de diversos povos, com cultura, crenças, mitos e tradições bastante peculiares, resultante da miscigenação dos povos que aqui habitavam, com os que para cá vieram, a exemplo, os nordestinos que vieram para a região extrair o látex da seringueira.
\end{abstract}

Palavras-chave: Disputa de território; Exploração do látex; Criação do Acre.

\section{THE IMPORTANCE OF THE ACREAN REVOLUTION IN THE FORMATION PROCESS OF THE STATE OF ACRE}

\begin{abstract}
This article describes the historical period of annexation of Acre to Brazilian territory, addressing events ranging from the agreements signed between Portugal and Spain, to a series of conflicts arising from economic interests, which culminated in the armed movement known as the "Acre Revolution" and, signing of the Treaty of Petrópolis, in 1903, when the region came to definitively belong to Brazil. Acre was declared Federal Territory in 1904 and only in 1962 did it become a Federation Unit. Thus, the objective was to discuss the importance of the Acre Revolution for the formation of the Acre territory.
\end{abstract}


For this purpose, a qualitative bibliographic and documentary research was carried out, as it is suitable for exploratory studies and the use of elaborated material, consisting mainly of books and scientific articles. In terms of occupation, it is possible to infer that the Acre Revolution was fundamental for the lands, which were included in the old Bolivian maps as "tierras nom descubiertas", to be annexed to Brazil. This armed struggle involving Brazilians and Bolivians, generated a considerable increase in national wealth, as well as originating a mixed society of different people, with very peculiar culture, beliefs, myths and traditions, resulting from the miscegenation of those who lived here, with those who came here, for example, the northeasterners who came to the region to extract the latex from the rubber tree.

Keywords: Territory dispute; Latex exploration; Creation of Acre.

\title{
LA IMPORTANCIA DE LA REVOLUCIÓN ACREAN EN EL PROCESO DE FORMACIÓN DEL ESTADO DE ACRE
}

\begin{abstract}
Resumen
Este artículo describe el período histórico de la anexión del Acre al territorio brasileño, describiendo hechos que van desde los acuerdos firmados entre Portugal y España, hasta la serie de conflictos producto de intereses económicos, que culminaron en el movimiento armado conocido como la "Revolución Acreana" y, firma del Tratado de Petrópolis, en 1903, en el cual la región pasó a pertenecer definitivamente a Brasil. El Acre fue declarado Territorio Federal en 1904 y solo en 1962 se convirtió en Unidad de la Federación. Así, el objetivo fue discutir la importancia de la Revolución Acreana para la formación del territorio del Acre. Para esto se realizó una investigación bibliográfica y documental cualitativa, por ser apta para los estudios exploratorios y el uso de material elaborado, constituido principalmente por libros y artículos científicos. En términos de ocupación, es posible inferir que la Revolución del Acre fue fundamental para que las tierras, que estaban incluidas en los antiguos mapas bolivianos como "tierras no descubiertas", fueran añadidas a Brasil. Esta lucha armada que involucró a brasileños y bolivianos, generó un aumento considerable de la riqueza nacional, además originó una sociedad mezclada de diferentes pueblos, con una cultura, creencias, mitos y tradiciones muy peculiares, resultado del mestizaje de los pueblos que aquí pasaron a vivir, con los que ya poblaban la región, por ejemplo, gente del Nordeste que llegaba a la región para extraer látex del árbol del caucho.
\end{abstract}

Palabras clave: Disputa territorial; Exploración de látex; Creación de Acre.

\section{INTRODUÇÃO}

"O acreano foi o único povo que lutou para ser brasileiro", essa expressão acabou se tornando a máxima na qual é forjada a identidade da população acreana, o acreano é brasileiro por uma excepcionalidade, uma vez que a história do Acre não faz parte daquilo que é tido como normal, mas sim, da escolha de ser brasileiro, que foi assentada na origem da luta armada conhecida como Revolução Acreana, ou seja: na luta por ser brasileiro, Morais (2016, p.5).

A autora esclarece, em sua obra 'Acreanidade’ Invenção e reinvenção da Identidade acreana, que esse conceito, apesar de usual por alguns pesquisadores é um tanto equivocado, uma vez que a identidade histórica é pautada em "relações e projetos de poder", liderados por aqueles que estão ou estiveram no topo, e portanto, decidem sobre a construção da identidade que é "uma construção social marcada por relações de poder econômico, político, social, cultural, simbólico", e não apenas por um sentimento nacionalista (ibid.). 
Assim, na abordagem de anexação do Acre ao Brasil, há pesquisadores e/ou escritores, a exemplo de Narloch (2011, p. 224), que acreditam ter a origem dos conflitos no fato de o governo brasileiro não se interessar pelas terras do Acre, tentando "livrar-se" por três vezes, sendo a primeira vez em 1867, com a assinatura do Tratado de Ayacucho, quando, segundo esse autor "o imperador dom Pedro II queria agradar os vizinhos e evitar que estes armassem confusão".

Observa-se aqui, que em 1867, o processo de extração do látex da seringueira estava em sua fase inicial, e que portanto, não era fator potencializador da economia regional, ocorrendo a aceleração desse processo somente na década seguinte. O Brasil estava envolvido na guerra do Paraguai e assinou o acordo diplomático (Tratado de Ayacucho), no qual o Estado brasileiro reconhecia que as terras da região acreana pertenciam à Bolívia, visando, manter a nação boliviana neutra no conflito (CALIXTO, 2003; SOUZA, 2005).

Em 19 de fevereiro de 1895, pressionado pela Bolívia, o governo brasileiro mandou, em missão chefiada por Thaumaturgo de Azevedo, uma equipe para localizar as nascentes do rio Javari e fazer as medições que determinavam os limites entre Brasil e Bolívia. Tal missão não foi concluída em virtude de Thaumaturgo de Azevedo observar a quantidade de seringueiros brasileiros existentes na região, sendo esses limites estabelecidos por outra comissão chefiada por Cunha Gomes, em 1898, que respeitou o que havia sido estabelecido no Tratado de Ayacucho, ficando assim definido que o que estivesse ao Norte da Linha Cunha-Gomes pertencia ao Brasil e o que estivesse ao Sul, seria da Bolívia, de modo que o Acre era incontestavelmente boliviano (SOUZA, 2005).

A terceira tentativa do governo brasileiro livrar-se do Acre, ainda de acordo com Narloch (2011, p. p.224-226), teria sido ainda em 1898, quando o ministro da Relações Exteriores, Dionísio Cerqueira enviou telegrama ao governo do Amazonas pedindo para este "concordar no estabelecimento do posto aduaneiro à margem do Rio Acre, ou Aquiri, em território incontestavelmente boliviano".

Nesse contexto, observa-se que se o Acre pertencia a Bolívia, não havia razões para impedir sua administração, não se interessando, o Brasil pelas terras do Acre à primeira vista, pois tendo os rios como vias principais de circulação, toda a produção regional (brasileira ou não), obedecia a centralidade de Manaus, fazendo que o Brasil já tivesse o maior controle sobre a produção gomífera, e portanto, não necessitando demonstrar maior interesse nas terras acreanas. 
Assim, de acordo com a historiografia oficial, a incorporação do Acre ao território brasileiro só ocorreu após um longo processo de disputa pelas terras, que culminou com o conflito armado conhecido como "Revolução Acreana", quando as terras produtoras de borracha foram palco de vários confrontos entre brasileiros e bolivianos, que disputavam o domínio do território (SOUZA, 2005).

Tais confrontos foram iniciados, principalmente quando o governo brasileiro passou a temer a implantação de uma superpotência, como já havia a ameaça, por ocasião da assinatura do contrato entre o governo boliviano e o presidente do Bolivian Sindycate, que associado a U.S. Rubber Co., compraria toda borracha produzida na região acreana, ficando a Bolívia com $60 \%$ dos lucros e com a tarefa de construir um canal que uniria o Acre aos rios Ortón e Madre de Dios. (TOCANTINS, 2001; BANDEIRA, 2000).

Antes de adentrarmos à história acreana, se faz necessário observar que no período das grandes navegações, Portugal e Espanha fizeram acordo diplomático dividindo as terras descobertas. O Tratados de Tordesilhas, assinado por esses dois países em 7 de junho de 1494, delimitava, por meio de uma linha imaginária, as posses portuguesas e espanholas. Tudo que ficasse a oeste da linha pertenceriam a Espanha e tudo que ficasse a leste pertenceriam a Portugal. Em consonância com esse tratado, grande parte do que temos hoje como território brasileiro era espanhol, inclusive o Acre que ficava totalmente do lado da linha pertencente à Espanha (TULUX, 2015).

De 1580 a 1640, a crise atrelada à sucessão do trono de Portugal levou a União Ibérica a unificar as coroas. Durante essa união houve o afrouxamento das linhas estabelecidas pelo Tratado de Tordesilhas, o que facilitou o processo de interiorização do Brasil, promovido pelas entradas e bandeiras ${ }^{1}$, o tratado não foi respeitado. No século XVII, os portugueses chegaram a ocupar parte da região amazônica, desenvolvendo assim atividades econômicas como a coleta de "drogas do sertão" (SOUZA, 2005)

Em 1750, o Tratado de Tordesilhas perdeu seus poderes, sendo o acordo atualizado por meio do Tratado de Madri. A Espanha visava barrar o avanço dos portugueses em suas terras, e Portugal buscou assegurar a ocupação já realizada, para tanto, utilizou-se do princípio do Uti Possidetis $^{2}$, princípio originado na máxima romana: uti possidetis, ita possideatis, que afirma

\footnotetext{
${ }^{1}$ Expedições pioneiras, realizadas com o objetivo de procurar riquezas minerais (pedras preciosas, ouro e prata) e coletar as "drogas do sertão", além de caçar índios para mão de obra escrava.

${ }^{2}$ Princípio de direito internacional segundo o qual os que de fato ocupam um território possuem direito sobre este. A expressão advém da frase uti possidetis, ita possideatis, que significa "como possuís, assim possuais".
} 
que quem possui de fato, deve possuir de direito, em outras palavras, "a terra pertence a quem a ocupa" e não a quem a descobre. Ainda assim, a região acreana continuava dentro do território espanhol (GÓES, 1900).

Com a independência dos países da América do Sul, os tratados de limites passaram a ser negociados pelas nações libertadas da Espanha e Portugal. Pelas cláusulas estabelecidas no Tratado de Ayacucho, assinado em 1867, a Bolívia era proprietária da região acreana. No entanto, o princípio do Uti Possidetis foi incluído no texto do acordo e nessa época já estava havendo a ocupação de alguns seringais acreanos por brasileiros, porém, a ocupação do território acreano propriamente dita, só ocorreu na fase de predominância do extrativismo da borracha, quando nordestinos, principalmente originários do Ceará, vencidos pela seca e por suas necessidades econômicas, aventuraram-se na floresta amazônica para extrair o látex da seringueira, produto considerado pelo mercado internacional como "ouro negro" (SOUZA, 2005; TOCANTINS 2001).

Assim, a instalação de uma Alfândega, em 1898, pelo Ministro Plenipotenciário boliviano José Paravicini, para cobrar impostos sobre a borracha produzida nos seringais acreanos, incomodou os seringalistas brasileiros que ali haviam se instalados, que passaram a protestar juntamente com os políticos e o governo do Amazonas, que estava perdendo parte dos impostos cobrados da borracha produzida na região e que passava por seus postos fiscais. Ameaçados pela presença boliviana, o governador do Estado do Amazonas, Ramalho Júnior e seringalista da região tomaram diversas medidas para dificultar a estadia boliviana, chegando inclusive a proibir o tráfego boliviano a partir de Manaus (TOCANTINS, 2001).

Diante de tudo, questiona-se: qual a importância da Revolução Acreana para a formação do território acreano?

Destarte, esse artigo tem por objetivo discutir a importância da Revolução Acreana para a formação do território acreano, iniciando pelos principais motivos que levaram a cobiça das terras estrangeiras. Para fins desse estudo, organizou-se o texto em seções, que detalham os materiais e métodos utilizados, no intento de alcançar o objetivo proposto, passando pela discussão sobre o processo de criação do Estado do Acre, no contexto da "Revolução Acreana".

\section{MATERIAIS E MÉTODO}

Para a consecução deste trabalho foi realizada pesquisa de natureza qualitativa, do tipo bibliográfica e documental, subsidiada em Gil (2002), por se adequar aos estudos exploratórios e a utilização de material elaborado, constituído principalmente por livros e artigos científicos. 
De acordo com este autor, a pesquisa bibliográfica é um tipo de pesquisa indispensável nos estudos históricos, por nos permitir um conhecimento mais aprofundado dos fatos. Os principais autores utilizados na pesquisa foram: Bandeira (2000), Cardoni (1986), Calixto (2003), Giraldo (1999), Góes (1900), Morais (2016), Narloch (2011), Paravicini (1900), Souza, (2005), Souza (2001), Souza, (2017), Tulux (2015), Tocantins (2001), dentre outros que versam sobre a criação e formação do Estado do Acre.

A pesquisa foi desenvolvida com a utilização de descritores tais como: criação do estado do Acre, Acre e processo de formação, História do Acre, nome de autores e principalmente, obras relacionadas ao tema, seguido de busca nas plataformas Google Acadêmico, Scielo e com amigos, selecionando-se livros e/ou capítulos de livros e artigos que tratam dos temas ora abordados, compondo material necessário ao embasamento teórico para escrita do presente trabalho, culminando com os resultados e discussão, com ênfase na temática Revolução Acreana, retomando tudo sucintamente nas considerações finais.

\section{RESULTADOS E DISCUSSÃO}

\subsection{A cobiça do território: questões primárias}

O Acre foi oficialmente integrado ao território brasileiro na Primeira República, com a assinatura do Tratado de Petrópolis, em 1903. A incorporação do Estado do Acre ao território brasileiro envolveu um longo processo conflituoso, que para Calixto (2003), teve como causa primária aspectos políticos e econômicos. Esse autor afirma que, entre 1873 e 1896, a deflação fez com que o nível britânico de preço declinasse em $40 \%$, ocasionando a queda nas taxas de lucro. "Estremeceram os alicerces que sustentavam os valores da livre troca" Calixto, (2003, p. 24). Desse modo, a abertura ao livre comércio não era suficiente para manter a Grã-Bretanha na posição principal. "O capital mobilizado politicamente exigiu do Estado proteção contra a intensa concorrência internacional (Id. Ibid.).

Foi a partir desse contexto que:

\footnotetext{
A borracha inseria-se, assim, nos planos dos fomentadores da modernidade [...]. À medida que o processo de vulcanização possibilitava um uso industrial da goma elástica, cada vez mais diversificado, cresciam os investimentos no setor, implicando a necessidade de suprimento de matéria-prima (CALIXTO, p. 31).
}

O processo de vulcanização, método criado em 1839 pelo norte-americano Charles Goodyear, acelerou o crescimento da indústria automobilística, e o uso dos pneus de borracha aumentaram a procura por áreas produtoras do látex, que passou a ser matéria prima das 
indústrias internacionais. Assim, o aumento do consumo do látex nas indústrias internacionais fez com que aumentasse consideravelmente a produção da borracha, e a região do atual estado do Acre era riquíssima em hevea brasiliensis. Esse fato fez com que as terras acreanas fossem supervalorizadas, gerando disputa pelo território, que culminou com a Revolução Acreana e assinatura do Tratado de Petrópolis em 1903 (CALIXTO, 2003).

Mas vamos aos fatos: a partir do acordo assinado em 1750, entre Portugal Espanha, que ficou conhecido como Tratado de Madri, foi criado, na região amazônica, a linha MadeiraJavari, "ponto histórico de partida para a existência do Acre", porém, tal linha que não chegou a ser demarcada. Entretanto, esse acordo não agradou aos padres jesuítas nem aos índios, que viviam em Sete Povos das Missões (Uruguai e parte do Rio Grande do Sul), cujo domínio passou a pertencer a Portugal. Os padres não podiam mais catequizar e os índios eram avessos aos portugueses. Para resolver a questão, Espanha e Portugal assinaram um novo acordo, o Tratado de Prado, que anulou o Tratado de Madri, voltando a valer as disposições do Tratado de Tordesilhas, assinado entre os dois países em 1494. Pelo Tratado de Prado o Acre continuava a pertencer a Espanha (TULUX, 2015; CHAVES, 2014).

Entretanto, após mais de uma década, Espanha e Portugal passaram a disputar a região de Sacramento (atual Uruguai) cedido por Portugal à Espanha no Tratado de Madri. Para resolverem a questão, assinaram um novo acordo, em $1^{\circ}$ de outubro de 1777 , ao qual denominaram de Tratado de San Ildefonso, no qual a Espanha continuou com o domínio de Sacramento e Sete Povos das Missões, ficando Portugal com o direito de uti possidetis, sua soberania sobre a margem esquerda do Rio da Prata e faixas territoriais da região sul de Santa Catarina, sendo este o último acordo firmado entre Portugal e Espanha e, as terras acreanas continuavam sobre o domínio da Espanha (GIRALDO, 1999).

Em 27 de março de 1867, Brasil e Bolívia, visando definir suas fronteiras, assinaram o Tratado de Ayacucho, estabelecendo a linha Beni-Javari, em substituição à primitiva linha Madeira-Javari, com início da linha na foz do rio Beni, entretanto, por conta do difícil acesso às coordenadas geográficas da nascente do rio Javari, tornou-se impossível executar o traçado da fronteira.

De acordo com Cardoni (1986, p. 2) a colonização do Acre teve como precursor um cearense chamado João Gabriel de Carvalho e Mello, que atraído pela Amazônia viajou para Belém, empregando-se na casa aviadora do português Visconde da Santo Elias, conquistando a confiança deste que "forneceu-lhe dinheiro e mercadoria para a exploração da borracha no 
Purus" Em 1875, João Gabriel já sendo um homem de recursos, retornou ao Ceará para buscar a família para trabalharem no Acre.

A esse fornecimento de mercadorias e outros artefatos deu-se o nome de aviamento. O sistema de aviamento funcionou como mecanismo de controle do capital comercial, durante o primeiro e segundo surto da borracha, gerando um processo de troca da borracha produzida pelos seringueiros por outros produtos necessários à permanência nos seringais. Assim, a troca funcionava "entre Seringueiros/Seringalistas/Casas Aviadoras e casas Exportadoras (SOUZA, 2005, p. 80, grifos do autor).

A partir de então, ocorreram milhares de outras ocupações, principalmente por egressos dos sertões nordestinos que fugiam da seca de 1877 e eram agenciados pelos novos seringalistas ou patrões, povoando a região, até então desabitada pelo homem branco e iniciando, assim, a conquista do território acreano.

Para Souza (2005), do ponto de vista do processo de ocupação, as terras acreanas deveriam pertencer a população indígena, que ocuparam e colonizaram a região muito antes da chegada do "homem branco" (nordestinos, bolivianos, dentre outros), enumerando várias tribos que aqui existiam antes da chegada dos brasileiros e bolivianos, que não tiveram como defender as terras e suas riquezas dos invasores por falta de armamentos adequados, vivendo hoje, em pequenas reservas.

Souza (2017), que divide o processo de ocupação das terras acreanas em "momentos históricos" pontua que antes da ocupação propriamente dita, houve a vinda dos "desbravadores" com o intuito de buscar produtos, informações e até com a missão de pacificar os índios. Esse autor cita personagens como João Rodrigues Cametá, Serafim Salgado, Manoel Clementino Carneiro Cunha, Manoel Urbano e tantos outros que de 1852 até 1866, além de visar conhecer geograficamente a região, também tinham por objetivo dominar os povos indígenas que aqui viviam.

A necessidade de pacificar os índios tinha dois objetivos: o primeiro era minimizar os obstáculos que eles representavam, uma vez que, em um primeiro momento, ofereciam resistência e tentavam defender seus territórios; em segundo, poderiam ser "mão de obra útil para exploração" (SOUZA, 2017, p.87).

Para Calixto (2003) "A chegada dos primeiros patrões "às tierras non descubiertas", como eram definidas as terras acreanas nos mapas bolivianos, ocorreu num momento em que a demanda internacional por borracha surgiu e os preços cresciam assustadoramente. Esse autor pontua que com a explosão do "boom gomífero" houve uma "acelerada subordinação do capital 
comercial das Casas Aviadoras ao capital da haute finance, representado, na Amazônia pelas Casas Exportadoras e bancos estrangeiros" (CALIXTO, p. 35).

$\mathrm{O}$ crescimento da demanda internacional e dos preços provocou uma acirrada disputa pelo controle das exportações do chamado ouro negro, pois quando a borracha passava pelo processo de vulcanização transformava-se em uma bola preta chamada de pele. As poucas casas exportadoras tinham o domínio da exportação e impunham seus preços de modo a deter o controle das fontes abastecedoras do látex. Esse fator teve como consequência regional, o investimento dos governos do Amazonas e Pará nas empresas de transportes.

Assim, no ano de 1878, em Belém cobrava-se

[...] um imposto de $3 \%$ sobre o embarque da borracha que, por cabotagem, chegava até Belém". Manaus e Belém concorriam no quesito portos exportadores da borracha. "Se, em 1890, a arrecadação da receita regional (Amazonas e Pará) era de 17.745 contos de réis, em 1900 saltava para 88.962, uma diferença percentual superior a 500\%" (CALIXTO, 2003 p. 38).

A Bolívia que até então considerava a região como Tierras nom descubiertas (terras não descobertas) em seus mapas antigos, resolveu exigir o reconhecimento do Acre como terras bolivianas, com base em acordos diplomáticos assinados anteriormente. Em 1899, passa a ocupar uma área, onde estabelece uma alfândega, a qual nominou de Puerto Alonso no atual município de Porto Acre-AC. As normas baixadas pelo Ministro boliviano Plenipotenciário ${ }^{1}$ Paravicini trouxeram implicações de ordem social e econômicas, uma vez que o "decreto declarava abertos os rios Acre, Iaco e Purus à navegação internacional" (CARDONI, 1986, p. 3)

Nesse cenário, Calixto (2003), observa que o Tratado de Ayacucho, firmado em 1867, no contexto do liberalismo do partido progressista, que estava no poder, foi assinado sem que ambos os países conhecessem um palmo da região entre os rios Madeira e o Javari. Assim, com a definição dos limites nesse tratado, o Estado do Amazonas perderia a zona mais rica e mais produtiva de seu território que compreendia a região do alto rio Acre, todo o Iaco e o alto rio Purus. "Naquele ano - 1898 - cerca de 23.108 toneladas de goma elástica eram exportadas, via portos de Belém e Manaus, ao preço altíssimo de 10.560 réis o quilo" (CALIXTO, 2003, p. 99).

Após concessão de permissão assinada pelo Ministro brasileiro Dionísio Cerqueira, para adentrar no Acre e estabelecer postos aduaneiro, Paravicini chega ao Rio Acre ou Aquiri a 3 de janeiro de 1899, "principia, de jure e de fato, a institucionalização do poder boliviano". Na

\footnotetext{
${ }^{1}$ No âmbito do direito internacional, um ministro plenipotenciário é um chefe de missão diplomática de categoria imediatamente inferior à de embaixador extraordinário e plenipotenciário
} 
alfândega de Porto Acre deveriam ser arrecadados os impostos de importação e exportação de mercadorias, produtos naturais e manufaturados, conforme as leis tratadas e regulamentos vigentes e os que forem expedidos (CALIXTO, 2003, pp. 112-113).

Diante desses acontecimentos, as casas aviadoras do Amazonas e do Pará e também os correspondentes dos governos estaduais reagiram ao fato dos tributos passarem a ser recebidos pelos bolivianos. Assim, acusaram o governo brasileiro de liberalismo contrário aos interesses da nação, uma vez que reconhecia o domínio estrangeiro, sem contestar, em uma área ocupada por brasileiros natos a mais de trinta anos.

O governador do Amazonas, Ramalho Júnior e a maioria dos seringueiros, inconformados com a situação, continuaram seus planos de não deixar a Bolívia se apossar das terras acreanas, mesmo que para isso tivessem que ir contra as ordens do governo brasileiro, que considerando que a "Linha Cunha Gomes", determinava que as terras pertenciam a Bolívia. Foi assim que o cearense José de Carvalho, advogado e jornalista, patrocinado pelo governo do Amazonas, veio para o Acre montar um plano de expulsão dos bolivianos (SOUZA, 2005).

\subsection{O início do conflito}

No seringal Bom Destino (atual município de Porto Acre), de propriedade de do sr. Joaquim Victor, José de Carvalho e os seringalistas traçaram seus planos para expulsar o delegado Santivenez Bezerra (2005). Partindo do seringal Caquetá, acompanhado de um grande número de seringueiros armados, chegaram a Puerto Alonso, no dia $1^{\circ}$ de maio de 1899 , às nove horas da manhã e intimaram "o Delegado Moisés Santivanez a deixar o Acre, numa demonstração clara de expulsão dos bolivianos das terras acreanas". O autor, que denomina esse ato de "primeira Insurreição contra o governo boliviano no Acre", pontua que não houve troca de tiros, nem sangue derramado. Santivanez deixou o Acre pacificamente (SOUZA, 2005, p. 152).

Porém, a Bolívia não desistiria facilmente e recorreu aos Estados Unidos, arquitetando uma maneira de possível arrendamento das terras aos empresários americanos e ingleses, para não perder a região acreana. Entretanto, essa negociação foi descoberta pelo espanhol Luiz Galvez Rodrigues de Arias, que na época, era repórter do jornal "A Província do Pará", em Belém, e fez chegar ao conhecimento do governador Pais de Carvalho, do estado do Pará, que o Ministro Paravicini estava prestes a firmar acordo com os Estados Unidos, no qual deveria assegurar a soberania das terras acreanas, mediante concessões aduaneiras e territoriais de 
grande porte. A reportagem publicada por Galvez abalou toda a opinião pública brasileira (BEZERRA, 2005).

\subsection{Primeiro ensaio do conflito: o Estado Independente do Acre e o imperador Galvez}

Com o apoio do governo do Amazonas, Galvez decidiu chefiar uma expedição ao Acre, porém, o fez na surdina para não demonstrar oposição ao governo federal. Ao sai de Manaus leva consigo seringueiros e autoridades, passando-se por um homem de negócios até desembarcar no seringal São Jerônimo, sede da Junta Revolucionária-JRA, liderada pelo cearense José de Carvalho, da qual fazia parte seringalistas, comerciantes e outras figuras que se opunham ao domínio da Bolívia, dando ciência do acordo secreto entre Bolívia e Estados Unidos, fato que os convenceu a aderirem seus planos (CALIXTO, 2003).

Calixto (2003, p.152) considera que esse encontro já era algo há muito planejado, pois de acordo com "um precioso documento, Galvez mantinha ligações com a Junta Revolucionária do Acre, organizada desde 24 de fevereiro de 1899 e da qual era representante no Pará e Amazonas".

Nesse contexto que no dia 14 de julho de 1899, com apoio da JRA, em Puerto Alonso, diante dos seringalistas e do povo, Galvez declarou o Estado Independente do Acre e foi aclamado Presidente da República do Acre, usando, na ocasião, o lema "Pátria e Liberdade" constituiu os principais mistérios e nomeando os seus ministros (CALIXTO, 2003; PARAVICINI, 1900).

De acordo com Calixto (2003), o primeiro decreto de Galvez oficializou a Proclamação da República do Estado Independente do Acre e estabeleceu seus limites. A capital passaria a se chamar Cidade do Acre, localizando-se onde ficava Puerto Alonso. O segundo decreto tratou da adoção de uma bandeira para a nova república composta da seguinte forma: dois triângulos retângulos ligados pela hipotenusa, sendo o superior de cor amarela e o inferior de cor verde, tendo no vértice superior uma estrela vermelha, solitária.

Assim, nasceu os primeiros princípios da formação do que seria mais tarde o estado do Acre.

Assim, durante o período de oito meses, tempo que durou a República, o presidente assinou vinte e sete decretos, revelando pleno domínio da técnica legislativa e esplêndida visão conjuntural.

Entretanto, nem tudo era perfeito. O Decreto de $\mathrm{n}^{\circ} 10$, por exemplo, que versou "sobre a fundação de centros agrícolas e pastoris", não foi visto com bons olhos por aqueles que viviam 
exclusivamente dos lucros da borracha. $\mathrm{O}$ artigo de $\mathrm{n}^{\circ} 17$ previu e outorgou uma Constituinte na qual o povo tivesse plena participação.

[...] o estatuto político da pátria humanitária de Galvez [...]. Era a ordem, agora legitimada por uma Constituição [...]. Uma república humanitária com sistema presidencialista de governo, mas com eleições indiretas (CALIXTO, 2003, p. 160-161).

Alguns grupos de proprietários de seringais, bem como Xapuri, que era chamada pelos bolivianos de Mariscal Sucre, não estavam de acordo com o Estado Independente. Dentre os seringalistas que faziam oposição a Galvez é citado como exemplo, Neutel Maia, dono do seringal Empresa (hoje Rio Branco, capital do Estado do Acre), Capitão Leite Barbosa, dono do seringal Humaitá (localizado em Porto Acre) e os seringalistas de Xapuri. Estes últimos, que viam Galvez como Invasor, chegaram a criar uma "Comissão Garantidora dos Direitos Humanos", e preferiram obedecer às ordens do governo brasileiro, como mencionado pelos autores:

\begin{abstract}
De Xapuri, Galvez receberia ofício assinado por Manoel Odorico de Carvalho, auto-intitulado 'Prefeito de Segurança Pública pela vontade soberana do povo', comunicando que, no Alto Acre, a população resolvia 'não aderir a essa revolução sem primeiro ouvir a decisão do governo brasileiro' [...]. Somavase a este movimento dissidente do Alto Acre, um outro que, sob a denominação de 'Comissão Garantidora dos Direitos Brasileiros', procurava, de todas as formas, minar o governo provisório. No Baixo Acre, para completar, havia, ainda, a propaganda anti-Governo Provisório, liderado por Neutel Maia do seringal Empresa e pelo Capitão Leite Barbosa do seringal Humaitá, este último outrora ativo colaborador na administração Paravicini (CALIXTO, 2003, p. 162).
\end{abstract}

As movimentações alcançaram maiores proporções quando o Embaixador Dom Félix Avelino Aramayo e Frederich Wilinfred, da empresa Car Whitrig, dos Estados Unidos, assinaram o contrato que constituía o "Bolivian Syndicate", formado por um capital inicial de 500.000 libras esterlinas, cujo objetivo era "explorar as riquezas naturais do território do Acre por um período de trinta anos, competindo-lhe auferir os proventos, sendo $60 \%$ dos quais reservados para a Bolívia e 40\% para o sindicato" (SOUZA, 2005, p.155).

Estes movimentos tiveram como consequências o banimento de Galvez da presidência, assumindo em seu lugar Antônio de Souza Braga, no dia 28 de dezembro de 1899, por aclamação, como novo presidente do Estado Independente do Acre (SOUZA, 2005).

"Além da linha do equador tudo é permitido" (Provérbio quinhentista português) "Nem tudo" (Luiz Galvez, deposto). (Excerto introdutório do livro Galvez Imperador do Acre. BEZERRA, 2005; SOUZA, 2001). 
Com a queda de Galvez, Puerto Alonso sob o domínio boliviano e a derrota da última expedição brasileira, a "dos Poetas" " como ficou conhecida, em 1901, o porto aduaneiro de Puerto Alonso teve uma renda de aproximadamente dois mil contos de réis. Com a pretendida instalação das alfândegas nos rios Iaco e Purus, esse valor poderia aumentar para oito vezes mais, somente com a exportação da borracha.

\begin{abstract}
O Bolivian Syndicate possuía liberdade de exercer e assegurar, até pela força, os seus direitos e privilégios no Acre [...] navegar tranquilamente por todos os rios acreanos, explorar as minas existentes no Acre [...] e se preciso fosse, poderia manter uma força armada de navios de guerra, para a defesa da região acreana (SOUZA, 2005, p. 154-155).
\end{abstract}

Quando a notícia da assinatura do contrato tomou proporções mundiais, Brasil e Peru reagiram. O Peru passou a se interessar pelas questões do Acre, principalmente, pela região do vale do Juruá, onde mantinha seus "caucheiros" trabalhando na extração do caucho. Após algumas negociações, os Estados Unidos, visando apoio do Brasil em suas intervenções armadas em países da América Central, convenceu a Bolívia a concordar em desfazer o contrato, uma vez que o Brasil pagaria a indenização.

Entretanto, antes de desfazer o acordo, a Bolívia, por meio de Dom Lino Romero, Delegado Nacional das Colônias, em Puerto Alonso, aumentou os impostos e as taxas de importação, baixou instruções marcando prazo improrrogável de seis meses para se fazer o registro, medições e demarcações dos seringais. Ao final deste período, os que não tivessem cumprido todas as etapas, perderiam seus direitos sobre a propriedade das terras que seriam declaradas como terras devolutas. Diante da urgência da situação, foi formada uma Junta Revolucionária, no seringal Caquetá, dia $1^{\circ}$ de julho de 1902, composta por Joaquim Victor, José Galdino, Rodrigo de Carvalho, Gentil Norberto e Plácido de Castro. Este último tinha um passado bem conhecido no Rio Grande do Sul, já tinha sido procurado por Rodrigues de Carvalho e outras figuras importantes da revolução, para entregar-lhe o comando das operações militares (BANDEIRA, 2000; TOCANTINS, 2001; SOUZA, 2005).

\title{
3.4 A Revolução Acreana com a chegada de um novo líder
}

Vasto verde estendal de campanha nativa, oficina ancestral das bravuras das raças, onde, ao grito revel do gaúcho que passa, tremula desdobrada uma

\footnotetext{
${ }^{1}$ Expedição Floriano Peixoto, conhecida como Expedição dos Poetas por ser composta, em sua maioria, por professores, poetas, advogados, médicos e engenheiros.
} 
flamula altiva.[...] (Aurélio Porto, A Campanha. IN: Valdir de Oliveira Calixto. Plácido de Castro e a construção da ordem no Aquiri, p. 175).

Plácido de Castro tinha 29 anos. Nascido em São Gabriel, Rio Grande do Sul, era bisneto, neto e filho de militares, além de já ter vasta experiência em guerras. Viera à Amazônia para trabalhar como agrimensor e só aceitou chefiar a revolução com a condição de que não houvesse interferência do governo de Manaus e que fosse constituída uma junta revolucionária totalmente obediente ao seu comando, sendo categórico em dizer que sem o aceite dessas condições preliminares, nada seria feito (CALIXTO, 2003).

Em pouco tempo, Plácido de Castro, tinha articulado um ambiente totalmente voltado para a revolução e a data em que o movimento seria deflagrado era dia 6 de agosto, por coincidir com a data da independência da Bolívia e, portanto, deveria ser de festa para os bolivianos. Estrategicamente escolheu Xapuri que na época era chamada pelos bolivianos de Mariscal Sucre, para o início da revolução, reuniu seu exército e deu início a sua guerra.

\footnotetext{
Posteriormente, em 7 de agosto de 1902, reunidos em Xapuri, na "Casa dos Srs Falk \& Vieira", reproclamava-se a independência do Acre, embora de fato ela já tivesse sido reproclamada no dia seguinte à deposição de D. Juan de Rios Barreto, Intendente de Xapuri, em 6 de agosto, data em que se comemora a independência da Bolívia (BEZERRA, 2005, p. 52).
}

Com a tomada da Vila Mariscal Sucre, em 6 de agosto de 1902, que volta a ser Xapuri, e exílio das autoridades bolivianas, Plácido delega a missão de consolidar a revolução, naquele local, a José Galdino e parte para visitar outros seringais com o intuito de recrutar homens e ensinar as artes militares (SOUZA, 2005).

Porém, avisado da tomada de Xapuri pelo exército acreano, o coronel boliviano Rezendo Rojas preparou uma emboscada e atacou as tropas de Plácido de Castro, no lugar chamado "Volta do Seringal Empresa" (atual Rio Branco), em 17 de setembro de 1902, dizimando grande parte dos soldados que compunham o batalhão acreano, fazendo seu líder recuar.

Plácido de Castro precisou recompor suas tropas e preparar militarmente cada soldado para atacar o Seringal Empresa e derrotar o exército boliviano. A batalha durou de 5 a 14 de outubro de 1902, quando "os soldados bolivianos vencidos pelas dos seringueiros acreanos e pela fome" tiveram que se render. Souza (2005, p. 156). De modo que, após cento e oitenta dias de confrontos armados entre as tropas brasileiras e as bolivianas, Plácido de Castro dominava todo o vale do rio Acre, com exceção do reduto de Puerto Alonso. 
Portanto, a Independência do Acre foi proclamada no dia 6 de agosto, porém, a tomada de Porto Acre se deu somente em 24 de janeiro de 1903, cinco meses depois, com a rendição boliviana. "Agora era organizar o Estado, a ordem recém proclamada nos altos rios acreanos" (CALIXTO, 2003, p. 202). Essa organização se deu por meio de decretos, cujo primeiro assim dispõe:

\author{
Decreto $n^{\circ} 1$. \\ Cidade do Acre [Puerto Alonso], 26 de janeiro de 1903. \\ José Plácido de Castro, Governador acclamado e commandante em chefe do \\ Exército do Estado Independente do Acre \\ Decreta: \\ A justiça civil, a criminal e a comercial do Estado Independente do Acre \\ ficarão sujeitas às disposições dos códigos, leis, decretos, etc, do E. U. do \\ Brasil até que seja promulgada a sua constituição. \\ Art. $2^{\circ}$. Serão válidos os títulos de propriedades definitivos ou provisórios o \\ presente expedido pela Bolívia ou pelo Estado do Amazonas, antes da \\ ocupação do Acre por este República. \\ Art. $3^{\circ}$. Fica sendo a língua official do Estado a portugueza. \\ Art, $4^{\circ}$. Fica considerado como typo monetário official do Estado Independente \\ do Acre o mesmo dos E. U. do Brasil, sendo o papel moeda desse paíz válido \\ aqui. \\ Art. $5^{\circ}$. Revogam-se as disposições em contrário. \\ (CALIXTO, 2003, p. 202-203).
}

Sendo os limites do Estado Independente traçados somente no $3^{\circ}$ decreto, datado de 28 de janeiro de 1903 e, com isso, tem-se mais um princípio para a formação do Acre com a delimitação dos seus limites e fronteiras.

Após assinatura dos primeiros decretos, Plácido de Castro não teve uma alternativa senão concordar com os termos do Modus Vivendi. Documento assinado entre Brasil e Bolívia, em 27 de março de 1867, cujo teor do artigo II preconizava que o território ao sul do paralelo de $10^{\circ}, 20^{\prime}$ era reconhecido como boliviano. Sendo designado para fazer cumprir o estipulado no acordo, o General Olympio. Assim, o decreto $\mathrm{n}^{\mathrm{o}} 7$ trata da transferência da sede do governo do Estado Independente do Acre para Xapuri.

Calixto (2003) pontua que nesse contexto houve um retrocesso, uma vez que o General Olympio da Silveira impõe sua ordem, depondo Plácido de Castro e proclamando em 13/05/1903, nestes termos, o fim da revolução:

Considerando que a quase totalidade do exército acreano revoltou-se contra o coronel José Plácido de Castro e seus auxiliares.

Considerando que este Chefe, levado por sentimentos de patriotismo que muito o recomenda a benemencia da sua amada Pátria, declarou retirar-se d'este Território e não querer tentar represálias afim de evitar uma lucta fraticida, deixando o Exército Nacional a guarda de mesmo território, conforme ficou estabelecido no Convenio de 21 de março findo. 
Considerando que em vista d'esta declaração do Coronel Plácido de Castro e da apresentação a este governo dos officiaes e praças de quase toda a força acreana, está extinta a Revolução (pág. 210-211).

Com a assinatura do Tratado de Petrópolis, acordo assinado pelo Barão do Rio Branco e Assis Brasil (Ministro brasileiros) e por Fernando Guachala e Cláudio Pinilha (Ministro bolivianos), terminava os conflitos entre brasileiros e bolivianos. O Acre passou a pertencer ao Brasil e os limites entre Brasil e Bolívia foram definitivamente traçados. Souza (2005). Na sequência, o governo brasileiro, por meio da lei 1.181, de 25 de fevereiro de 1904, organizou o Acre em Território Federal, dividindo-o em três departamentos autônomos, a saber: Alto-Acre, com sede em Rio Branco, Alto-Purus, com sede em Sena Madureira e Alto-Juruá, com sede em Cruzeiro do Sul, administrados por prefeitos de livre nomeação pelo Presidente da República. Isso, ao mesmo tempo em que consolidou o Acre como um lugar, também, assegurou a sua anexação a uma república, a federativa do Brasil.

Plácido de Castro foi nomeado prefeito do Departamento do Alto Acre em 24 de julho de 1906, permanecendo até 1907, quando voltou a trabalhar no seringal Capatará, de sua propriedade. SOUZA (2005, p.158) pontua que Plácido de Castro, durante sua atuação como líder da Revolução Acreana, "conseguiu alguns inimigos políticos", motivo pelo qual acabou por sofrer atentado, sendo vítima de uma emboscada, quando regressava de Rio Branco para o seringal Capatará, recebendo dois tiros pelas costas. No local da tragédia foi afixada uma placa em mármore com os seguintes dizeres:

Foi aqui que caiu ferido pelas balas de assassinos desnaturados o grande patriota acreano, coronel José Plácido de Castro, a 9 de agosto de 1908, imperecível lembrança dos seus admiradores e amigos (CARDONI, 1986, p. 284).

O Estado do Acre foi criado no contexto do conflito armado conhecido como "Revolução Acreana", e foi oficialmente integrado ao território brasileiro na Primeira República, com a assinatura do Tratado de Petrópolis (1903). Mas esse tratado não foi assinado gratuitamente. As condições para sua assinatura exigiam que o Brasil pagasse à Bolívia a quantia de 2 mil libras esterlinas; que o Brasil construísse uma estrada de ferro (MadeiraMamoré), com um ramal que chegasse a Vila Bela, na Bolívia, visando a saída da produção boliviana para o Brasil, e ainda, que a Bolívia tivesse liberdade de transitar pela estrada de ferro Madeira-Mamoré e pelos rios acreanos.

Mas por que é importante o conhecimento desses fatos históricos? Bem, até recentemente o Acre era tido como inexistente para muitas pessoas, ou se existia, não fazia 
parte do território brasileiro. Até houve campanha para provar que o Acre existe, uma vez que a maior referência que temos, em nível nacional e internacional, é Chico Mendes.

O desconhecimento da história local aumentou ainda mais a partir da mudança no sistema de seleção para o ingresso nos cursos superiores (antes vestibular e atualmente ENEM), quando deixou de ser cobrada questões sobre a história acreana, gerando um "silenciamento" e uma possível perda da identidade cultural à toda sociedade acreana, que passa a ser privada do pleno conhecimento da história da criação e formação do Estado do Acre. Como valorizar o Acre, se nem mesmo seus habitantes conhecem a sua história?

Quem sabe que aqui existiam, antes da chegada dos brasileiros e bolivianos, milhares de indígenas, com língua, sua cultura, seus costumes e suas tradições? Quem sabe que para cá vieram os nordestinos fugindo da seca e também em busca de dias melhores e que foram exatamente esses homens que se tornaram soldados-seringueiros do exército acreano, e que sob o comando de Plácido de Castro combateram na Revolução Acreana? A maioria de nós somos bisnetos ou netos de nordestinos e indígenas, não esquecendo outros povos como os sírios e libaneses que são partes da formação e constituição da sociedade acreana.

É com referência a essas questões que alguns autores, criticam a história contada "pela voz da colonização dita civilizatória", em virtude de esse tipo de historiográfica considerar (mesmo se esforçando para não parecer), os povos que aqui viviam (nativos) e os que para cá vieram (nordestinos) "todos [...] como coisas/objetos prenhes de valor dispostos à livre exploração", motivo pelo qual (Souza, 2017), cunha a Revolução Acreana de "Revolução dos Proprietários", compreendendo que os maiores interessados na posse das terras acreanas, eram os donos de seringais, de casas aviadoras e exportadores do precioso ouro negro.

Calixto (2003), Souza (2017), Souza (2005) e Tocantins (2001) enfatizam que todo o movimento armado foi motivado pela riqueza advinda da produção de borracha na região acreana, que servia de matéria-prima às indústrias dos países europeus, principalmente Estados Unidos e Inglaterra. Na visão desses autores as terras acreanas pertenciam as populações indígenas que aqui habitavam bem antes da chegada dos nordestinos e bolivianos. Porém, estes povos não tiveram como defender seus territórios dos invasores, uma vez que não dispunham de armamento adequado.

\section{CONSIDERAÇÕES FINAIS}

Este trabalho procurou discorrer sobre o processo de criação e formação do Estado do Acre, com foco na luta armada conhecida como "Revolução Acreana", destacando os nomes 
dos personagens que mais se envolveram no referido processo. $\mathrm{O}$ artigo contextualizou, ainda que sucintamente, o panorama mundial que motivou os interesses de empresas nacionais e internacionais nas terras acreanas.

Ao considerar os materiais utilizados nesta pesquisa, pode-se notar que o Estado do Acre é o único estado da federação brasileira a ter uma "certidão de nascimento" assinada e reconhecida em cartório (Tratado de Petrópolis), acordo lavrado em 1903, após muitas batalhas, sangue derramado e várias negociações. Acordo que custou aos cofres brasileiros o valor de 2 mil Libras Esterlinas para que as terras estrangeiras passassem a integrar definitivamente ao território brasileiro.

De tudo exposto, é possível inferir que em termos de ocupação, a Revolução Acreana foi fundamental para que a região, antes considerada nos antigos mapas bolivianos como Tierras nom Descubiertas, fossem anexadas ao Brasil. Essa luta armada envolvendo brasileiros e bolivianos, gerou um acréscimo considerável às riquezas nacionais, assim como originou uma sociedade mista de diversos povos, com cultura, crenças, mitos e tradições bastante peculiares.

Entretanto, observa-se que, se o princípio do Uti Possidetis, fosse válido para as populações indígenas, estas seriam, sem dúvidas, as verdadeiras donas das terras acreanas, uma vez que aqui já habitavam antes de todo processo de ocupação pelo "homem branco", mas infelizmente, esse princípio foi inserido e válido somente nos acordados firmados entre Portugal e Espanha, que visavam assegurar a posse das terras por eles descobertas, no período das grandes navegações.

\section{REFERÊNCIAS}

ANDRADE, José H. Fischel de; LIMOEIRO, Danilo. Rui Barbosa e a política externa brasileira: considerações sobre a Questão Acreana e o Tratado de Petrópolis (1903). Rev. Bras. Polít. Int. v. 46 n. 1, p. 94-117, 2003.

BANDEIRA, Luiz Alberto Moniz. O Barão de Rothschild e a questão do Acre. Rev. Bras. Polít. Int. v.43, n.2, p. 150-169. 2000.

BEZERRA, Maria José. Invenções do Acre - de Território a estado - um olhar social... São Paulo. USP. Tese (Doutorado em História Social). Programa de Pós-Graduação em História. Instituto de Filosofia, Letras e Ciências Humanas, Universidade de São Paulo - SP, 2005.

CARDONI, Hélio Guimarães. A CONQUISTA DO ACRE: uma história em quadrinhos. 2 ed. Curitiba, Linarth, 1986. 
CALIXTO, Valdir de Oliveira. Plácido de Castro e a Construção da ordem no Aquiri: contribuição à história das idéias políticas. Rio Branco: FEM, 2003.

GIL, Antônio Carlos. Como Elaborar Projetos de Pesquisa. $4^{\mathrm{a}}$ ed. São Paulo: Atlas S.A., 2002.

CHAVES, Otávio Ribeiro. América Portuguesa: Do Tratado De Madri Ao Tratado De Santo Ildefonso (Portuguese America: From The Madrid Treaty To The Santo Ildefonso Treaty). Universidade Estadual de Mato Grosso. Revista Territórios \& Fronteiras, Cuiabá, vol. 7, n. 2, jul-dez., 2014.

GIRALDO, Manuel Lucena. Reformar as florestas: o tratado de 1777 e as demarcações entre a América espanhola e a América portuguesa. Revista OCEANOS - a formação territorial do Brasil. Lisboa: Núm. 40, outubro/Dezembro de 1999.

GÓES, Synésio Sampaio. Alexandre de Gusmão e o Tratado de Madrid. Revista OCEANOS a formação territorial do Brasil. Lisboa: Núm. 40, Outubro/Dezembro de 1999.

MORAIS, Maria de Jesus. "Acreanidade" Invenção e reinvenção da Identidade acreana. Rio Branco: Edufac, 2016.

NARLOCK, Leandro. Guia politicamente incorreto da história do Brasil. São Paulo: Leya, 2011.

SOUZA, Carlos Alberto de. História do Acre: novos temas, novas abordagem. Rio Branco: Editor Carlos Alberto de Souza, 2005.

SOUZA, Márcio. Galvez Imperador do Acre. Rio de Janeiro, São Paulo: Record, 2001.

SOUZA, João José Veras de. Seringalidade: o estado da colonialidade na Amazônia e os condenados da floresta. Manaus: Valer, 2017

TOCANTINS, Leandro: Formação histórica do Acre. 4. Edição- Brasília: Senado Federal, 2001.

TULUX, Bruno Mendes. A defesa do oeste colonial no contexto da segunda metade do século XVIII - O sul da capitania de Matto Grosso. Mneme - Revista de Humanidades. V. 9, n. 24. Caicó: UFRN, Set./out. 2008. Disponível em: www.cerescaico.ufrn.br/mneme/anais/. Acessado em 14/05/2021. 